\title{
COMMON FIXED POINT FOR WEAKLY COMPATIBLE MAPS IN METRIC SPACE
}

\author{
K. Jha \\ Department of Natural Sciences \& Mathematics, \\ School of Science, Kathmandu University, \\ P.O. Box No. 6250, Kathmandu, NEPAL. \\ Corresponding Author E-Mail: jhaknh@yahoo.co.in, jhakn@ku.edu.np.
}

\begin{abstract}
A common fixed point theorem involving two pairs of weakly compatible mappings is proved under a Lipschitz type contractive condition, which is independent of the known contractive definitions.
\end{abstract}

Keywords: fixed point, complete metric space, weakly compatible maps.

2000 Mathematics Subject Classification: 47 H 10, 54 H 25.

\section{INTRODUCTION}

The study of common fixed point of mappings satisfying contractive type conditions has been a very active field of research activity during the last three decades. The most general of the common fixed point theorems pertain to four mappings, say A, B, S and T of a metric space $(X, d)$, and use either a Banach type contractive condition of the form

$$
\mathrm{d}(\mathrm{Ax}, \mathrm{By}) \leq \mathrm{h} \mathrm{m}(\mathrm{x}, \mathrm{y}), 0 \leq \mathrm{h}<1,
$$

where $\mathrm{m}(\mathrm{x}, \mathrm{y})=\max \{\mathrm{d}(\mathrm{Sx}, \mathrm{Ty}), \mathrm{d}(\mathrm{Ax}, \mathrm{Sx}), \mathrm{d}(\mathrm{By}, \mathrm{Ty}),[\mathrm{d}(\mathrm{Sx}, \mathrm{By})+\mathrm{d}(\mathrm{Ax}, \mathrm{Ty})] / 2\}$,

or, a Meir-Keeler type $(\varepsilon, \delta)$-contractive condition of the form

given $\varepsilon>0$ there exists a $\delta>0$ such that $\varepsilon \leq \mathrm{m}(\mathrm{x}, \mathrm{y})<\varepsilon+\delta \Rightarrow \mathrm{d}(\mathrm{Ax}, \mathrm{By})<\varepsilon$,

or, a $\phi$-contractive condition of the form $\mathrm{d}(\mathrm{Ax}, \mathrm{By}) \leq \phi(\mathrm{m}(\mathrm{x}, \mathrm{y}))$,

involving a contractive gauge function $\phi: R_{+} \rightarrow R_{+}$is such that $\phi(\mathrm{t})<\mathrm{t}$ for each $\mathrm{t}>0$.

Clearly, condition (1) is a special case of both conditions (2) and (3). A $\phi$-contractive condition (3) does not guarantee the existence of a fixed point unless some additional condition is assumed. Therefore, to ensure the existence of common fixed point under the contractive condition (3), the following conditions on the function $\phi$ have been introduced and used by various authors.

(I) $\phi(\mathrm{t})$ is non decreasing and $\mathrm{t} /(\mathrm{t}-\phi(\mathrm{t}))$ is non increasing (Carbone et al. [2]),

(II) $\phi(t)$ is non decreasing and $\lim _{n} \phi^{n}(t)=0$ for each $t>0$ ( Jachymski [3]),

(III) $\phi$ is upper semi continuous (Boyd and Wong [1], Jachymski [3], Maiti and Pal [11], Pant [14]) or equivalently,

(IV) $\phi$ is non decreasing and continuous from right (Park and Rhoades [20]).

It is now known (e.g., Jachymski [3], Pant et al. [15]) that if any of the conditions (I), (II), (III) or (IV) is assumed on $\phi$, then a $\phi$-contractive condition (3) implies an analogous ( $\varepsilon$, $\delta$ )-contractive condition (2) and both the contractive conditions hold simultaneously. Similarly, a Meir- Keeler type $(\varepsilon, \delta)$-contractive condition does not ensure the existence of a fixed point. The following example illustrates that an $(\varepsilon, \delta)$-contractive condition of type (2) 
neither ensures the existence of a fixed point nor implies an analogous $\phi$-contractive condition (3).

Example 1. (Pant et al [15]) Let $\mathrm{X}=[0,2]$ and $\mathrm{d}$ be the Euclidean metric on $\mathrm{X}$. Define $\mathrm{f}: \mathrm{X}$ $\rightarrow \mathrm{X}$ by $\mathrm{fx}=(1+\mathrm{x}) / 2$ if $\mathrm{x}<1 ; \quad \mathrm{fx}=0$ if $\mathrm{x} \geq 1$. Then, it satisfies contractive condition $\varepsilon \leq \max \{\mathrm{d}(\mathrm{x}, \mathrm{y}), \mathrm{d}(\mathrm{x}, \mathrm{fx}), \mathrm{d}(\mathrm{y}, \mathrm{fy}),[\mathrm{d}(\mathrm{x}, \mathrm{fy})+\mathrm{d}(\mathrm{y}, \mathrm{fx})] / 2\}<\varepsilon+\delta \Rightarrow \mathrm{d}(\mathrm{fx}, \mathrm{fy})<\varepsilon$, with $\delta(\varepsilon)=1$ for $\varepsilon \geq 1$ and $\delta(\varepsilon)=1-\varepsilon$ for $\varepsilon<1$ but $f$ does not have a fixed point. Also $f$ does not satisfy the contractive condition $d(f x, f y) \leq \phi(\max \{d(x, y), d(x, f x), d(y, f y),[d(x, f y)+d(y, f x)] / 2\})$, since the desired function $\phi(t)$ cannot be defined at $t=1$.

Hence, the two types of contractive conditions (2) and (3) are independent of each other. Thus, to ensure the existence of common fixed point under the contractive condition (2), the following conditions on the function $\delta$ have been introduced and used by various authors

(V) $\quad \delta$ is non decreasing (Pant $[13,14]$ )

(VI) $\delta$ is lower semi continuous (Jungck [8], Jungck et al.[9]).

Jachymski [3] has shown that the $(\varepsilon, \delta)$-contractive condition (2) with a non decreasing $\delta$ implies a $\phi$-contractive condition (3). Also, Pant et al.[15] have shown that the $(\varepsilon, \delta)$ contractive condition (2) with a lower semi continuous $\delta$, implies a $\phi$-contractive condition (3). Thus, we see that if additional conditions are assumed on $\delta$ then the $(\varepsilon, \delta)$-contractive condition (2) implies an analogous $\phi$-contractive condition (3) and both the contractive conditions hold simultaneously.

It is thus clear that contractive conditions (2) and (3) hold simultaneously whenever (2) or (3) is assumed with additional condition on $\delta$ or $\phi$ respectively. It follows, therefore, that the known common fixed point theorems can be extended and generalized if instead of assuming one of the contractive condition (2) or (3) with additional conditions on $\delta$ and $\phi$, we assume contractive condition weaker than the condition (2) together with the following Lipschitz type condition of the form

$$
\begin{array}{r}
\mathrm{d}(\mathrm{Ax}, \mathrm{By})<\mathrm{k}[\mathrm{d}(\mathrm{Sx}, \mathrm{Ty})+\mathrm{d}(\mathrm{Ax}, \mathrm{Sx})+\mathrm{d}(\text { By, Ty })+\mathrm{d}(\mathrm{Sx}, \text { By })+\mathrm{d}(\mathrm{Ax}, \mathrm{Ty})], \\
\text { for } 0 \leq \mathrm{k} \leq 1 / 3 .
\end{array}
$$

We prove a common fixed point theorem for four mappings adopting this approach in this paper. This gives a new approach of ensuring the existence of fixed points under an $(\varepsilon, \delta)$ contractive condition consists of assuming additional conditions which are independent of the $\phi$-contractive condition implied by (V) and (VI). As the fixed point theorem is established removing the assumption of continuity, relaxing the compatibility to the weak compatibility property and also replacing the completeness of the space, this result generalizes and improves various other similar results of fixed points.

Two self-mappings $\mathrm{A}$ and $\mathrm{S}$ of a metric space $(\mathrm{X}, \mathrm{d})$ are called compatible (see Jungck [8]) if, $\lim _{n \rightarrow \infty} d\left(A S x_{n}, S A x_{n}\right)=0$, whenever $\left\{x_{n}\right\}$ is a sequence in $X$ such that $\lim _{n \rightarrow \infty} A x_{n}=\lim _{n \rightarrow \infty} S_{n}=t$ for some $t$ in $X$. It is easy to see that compatible maps commute at their coincidence points.

Two self mappings $\mathrm{A}$ and $\mathrm{S}$ of a metric space $(\mathrm{X}, \mathrm{d}$ ) are called weakly compatible (see Jungck and Rhoades [5]) if, they commute at coincidence points. That is, if $A x=S x$ implies that $\mathrm{ASx}=\mathrm{SAx}$ for $\mathrm{x}$ in $\mathrm{X}$. 
It is noted that a compatible maps are weakly compatible but weakly compatible maps need not be compatible (Singh and Mishra [24]).

To prove our theorem, we shall use the following Lemma of Jachymski [3]:

LEMMA (2.2 of Jachymski [3]): Let A, B, S and T be self mappings of a metric space (X, d) such that $\mathrm{AX} \subset \mathrm{TX}, \mathrm{BX} \subset \mathrm{SX}$. Assume further that given $\varepsilon>0$ there exists $\delta>0$ such that for all $\mathrm{x}$, $\mathrm{y}$ in $\mathrm{X}$

$$
\varepsilon<\mathrm{M}(\mathrm{x}, \mathrm{y})<\varepsilon+\delta \Rightarrow \mathrm{d}(\mathrm{Ax}, \mathrm{By}) \leq \varepsilon,
$$

and $\mathrm{d}(\mathrm{Ax}, \mathrm{By})<\mathrm{M}(\mathrm{x}, \mathrm{y})$, whenever $\mathrm{M}(\mathrm{x}, \mathrm{y})>0$

where $M(x, y)=\max \{d(S x, T y), d(A x, S x), d(B y, T y),[d(S x, B y)+d(A x, T y)] / 2\}$.

Then for each $\mathrm{x}_{0}$ in $\mathrm{X}$, the sequence $\left\{\mathrm{y}_{\mathrm{n}}\right\}$ in $\mathrm{X}$ defined by the rule

$$
\mathrm{y}_{2 \mathrm{n}}=\mathrm{Ax}_{2 \mathrm{n}}=\mathrm{Tx}_{2 \mathrm{n}+1} ; \mathrm{y}_{2 \mathrm{n}+1}=\mathrm{Bx}_{2 \mathrm{n}+1}=\mathrm{Sx}_{2 \mathrm{n}+2} \text { is a Cauchy sequence. }
$$

Jachymski [3] has shown that contractive condition (2) implies (4) but contractive condition (4) does not imply the contractive condition (2).

\section{The Main Result}

Theorem 1. Let $A, B, S$ and $T$ be self mappings of a metric space $(X, d)$ such that

(i) $\mathrm{AX} \subset \mathrm{TX}, \mathrm{BX} \subset \mathrm{SX}$,

(ii) given $\varepsilon>0$ there exists a $\delta>0$ such that for all $\mathrm{x}$, $\mathrm{y}$ in $\mathrm{X}$,

$$
\varepsilon<\mathrm{M}(\mathrm{x}, \mathrm{y})<\varepsilon+\delta \Rightarrow \mathrm{d}(\mathrm{Ax}, \mathrm{By}) \leq \varepsilon \text {, and }
$$

(iii) $\mathrm{d}(\mathrm{Ax}, \mathrm{By})<\mathrm{k}[\mathrm{d}(\mathrm{Sx}, \mathrm{Ty})+\mathrm{d}(\mathrm{Ax}, \mathrm{Sx})+\mathrm{d}(\mathrm{By}, \mathrm{Ty})+\mathrm{d}(\mathrm{Sx}$, By $)+\mathrm{d}(\mathrm{Ax}, \mathrm{Ty})]$,

for $0 \leq \mathrm{k} \leq 1 / 3$. If one of $\mathrm{AX}, \mathrm{BX}, \mathrm{SX}$ and $\mathrm{TX}$ is complete subspace of $\mathrm{X}$ and if the pairs (A, $\mathrm{S})$ and $(\mathrm{B}, \mathrm{T})$ are weakly compatible, then $\mathrm{A}, \mathrm{B}, \mathrm{S}$ and $\mathrm{T}$ have unique common fixed point.

Proof. Let $\mathrm{x}_{0}$ be an arbitrary point in $\mathrm{X}$. Define sequences $\left\{\mathrm{x}_{\mathrm{n}}\right\}$ and $\left\{\mathrm{y}_{\mathrm{n}}\right\}$ in $\mathrm{X}$ given by the rule

$$
\mathrm{y}_{2 \mathrm{n}}=\mathrm{Ax}_{2 \mathrm{n}}=\mathrm{Tx}_{2 \mathrm{n}+1} ; \mathrm{y}_{2 \mathrm{n}+1}=\mathrm{Bx}_{2 \mathrm{n}+1}=\mathrm{Sx}_{2 \mathrm{n}+2} \text {. }
$$

This can be done by virtue of (i). Since the contractive condition (ii) of this theorem implies the contractive conditions (4) and (5) of LEMMA( 2.2 of Jachymski [3]), so using this LEMMA, we conclude that $\left\{\mathrm{y}_{\mathrm{n}}\right\}$ is a Cauchy sequence in $\mathrm{X}$.

Suppose that TX is a complete subspace of $X$, then the subsequence $y_{2 n}=T_{2 n+1}$ is a Cauchy sequence in $T X$ and hence has a limit $u$. Let $v \in T^{-1} u$, then $T v=u$. Since $y_{2 n}$ is convergent, so $y_{n}$ is convergent to $u$ and hence $y_{2 n+1}$ also converges to $u$. Now, setting $x=x_{2 n}$ and $y=v$ in (iii) we have

$$
\begin{aligned}
\mathrm{d}\left(\mathrm{Ax}_{2 \mathrm{n}}, \mathrm{Bv}\right)<\mathrm{k}\left[\mathrm{d}\left(\mathrm{Sx}_{2 \mathrm{n}}, \mathrm{Tv}\right)+\mathrm{d}\left(\mathrm{Ax}_{2 \mathrm{n}}, \mathrm{Sx}_{2 \mathrm{n}}\right)+\mathrm{d}(\mathrm{Bv}, \mathrm{Tv})+\right. \\
\left.\mathrm{d}\left(\mathrm{Sx}_{2 \mathrm{n}}, \mathrm{Bv}\right)+\mathrm{d}\left(\mathrm{Ax}_{2 \mathrm{n}}, \mathrm{Tv}\right)\right] .
\end{aligned}
$$

Letting $\mathrm{n} \rightarrow \infty$, we have $\mathrm{d}(\mathrm{u}, \mathrm{Bv}) \leq 2 \mathrm{kd}(\mathrm{u}, \mathrm{Bv})$, which implies that $\mathrm{Bv}=\mathrm{u}$. Also, since $\mathrm{BX} \subset$ $\mathrm{SX}$, so $\mathrm{u}=\mathrm{Bv}$ implies that $\mathrm{u} \in \mathrm{SX}$. Let $\mathrm{w} \in \mathrm{S}^{-1} \mathrm{u}$, then $\mathrm{Sw}=\mathrm{u}$. Setting $\mathrm{x}=\mathrm{w}$ and $\mathrm{y}=\mathrm{x}_{2 \mathrm{n}+1}$ in (iii), we get

$$
\begin{aligned}
\mathrm{d}\left(\mathrm{Aw}, \mathrm{Bx}_{2 \mathrm{n}+1}\right)<\mathrm{k}\left[\mathrm{d}\left(\mathrm{Sw}, \mathrm{Tx}_{2 \mathrm{n}+1}\right)+\mathrm{d}(\mathrm{Aw}, \mathrm{Sw})+\mathrm{d}\left(\mathrm{Bx}_{2 \mathrm{n}+1}, \mathrm{Tx}_{2 \mathrm{n}+1}\right)+\right. \\
\left.\mathrm{d}\left(\mathrm{Sw}_{2} \mathrm{Bx}_{2 \mathrm{n}+1}\right)+\mathrm{d}\left(\mathrm{Tx}_{2 \mathrm{n}+1}, \mathrm{Aw}\right)\right]
\end{aligned}
$$

and letting $\mathrm{n}$ tend to infinity, we get $\mathrm{d}(\mathrm{Aw}, \mathrm{u}) \leq 2 \mathrm{kd}(\mathrm{u}, \mathrm{Aw})$ which implies that $\mathrm{u}=\mathrm{Aw}$. This means that $\mathrm{u}=\mathrm{Tv}=\mathrm{Bv}=\mathrm{Aw}=\mathrm{Sw}$.

Now, since $u=T v=B v$, so by the weak compatibility of $(B, T)$, it follows that $B T v=T B v$ and so we get $\mathrm{Bu}=\mathrm{BTv}=\mathrm{TBv}=\mathrm{Tu}$. 
Also, since $u=S w=A w$, so by the weak compatibility of $(A, S)$, it follows that ASw $=$ SAw and so we have $\mathrm{Au}=\mathrm{ASw}=\mathrm{SAw}=\mathrm{Su}$.

Thus, from (iii), we have

$$
\mathrm{d}(\mathrm{Aw}, \mathrm{Bu})<\mathrm{k}[\mathrm{d}(\mathrm{Sw}, \mathrm{Tu})+\mathrm{d}(\mathrm{Sw}, \mathrm{Aw})+\mathrm{d}(\mathrm{Tu}, \mathrm{Bu})+\mathrm{d}(\mathrm{Sw}, \mathrm{Bu})+\mathrm{d}(\mathrm{Tu}, \mathrm{Aw})] ;
$$

that is, $d(u, B u)<3 k d(u, B u)$ which is a contradiction for $0 \leq k<1 / 3$. This implies that $u=$ $B u$. Similarly, using (iii), one can show that $A u=u$. Therefore, we have $u=B u=T u=A u=$ $\mathrm{Su}$. Hence, the point $\mathrm{u}$ is a common fixed point of $\mathrm{A}, \mathrm{B}, \mathrm{S}, \mathrm{T}$.

If we assume $\mathrm{SX}$ is complete, then the argument analogue to the previous completeness argument proves the theorem. If $\mathrm{AX}$ is complete, then $\mathrm{u} \in \mathrm{AX} \subset \mathrm{TX}$. Similarly, if $\mathrm{BX}$ is complete, then $\mathrm{u} \in \mathrm{BX} \subset \mathrm{SX}$. So, the theorem is established. The uniqueness of the common fixed point follows easily from condition (iii).

This completely establishes the theorem.

We now give an example to illustrate the above theorem.

Example 2. Let $X=[2,20]$ and $d$ be the usual metric on $X$. Define $A, B, S, T: X \rightarrow X$ as follows: $A x=2$ for each $\mathrm{x}$;

$$
\begin{array}{cll}
\mathrm{Sx}=\mathrm{x} \text { if } \mathrm{x} \leq 8, & \mathrm{Sx}=8 \text { if } 8<\mathrm{x}<14, & \mathrm{Sx}=(\mathrm{x}+10) / 3 \text { if } 14 \leq \mathrm{x} \leq 17 \\
\text { and } & \mathrm{Sx}=(\mathrm{x}+7) / 3 \text { if } \mathrm{x}>17 ; & \\
\mathrm{Tx}=2 \text { if } \mathrm{x}=2 \text { or }>6, & \mathrm{Tx}=12+\mathrm{x} \text { if } 2<\mathrm{x}<4, & \mathrm{Tx}=9+\mathrm{x} \text { if } 4 \leq \mathrm{x}<5 \\
\text { and } & \mathrm{Tx}=8 \text { if } 5 \leq \mathrm{x} \leq 6 ; & \\
\mathrm{Bx}=2 \text { if } \mathrm{x}<4 \text { or } \mathrm{x}>6, & \mathrm{Bx}=3+\mathrm{x} \text { if } 4 \leq \mathrm{x}<5, & \mathrm{Bx}=2+\mathrm{x} \text { if } 5 \leq \mathrm{x} \leq 6 .
\end{array}
$$

Then $\mathrm{A}, \mathrm{B}, \mathrm{S}$ and $\mathrm{T}$ satisfy all the conditions of the above theorem and have a unique common fixed point $\mathrm{x}=2$. Being compatible mappings, all $\mathrm{A}, \mathrm{B}, \mathrm{S}$ and $\mathrm{T}$ are weakly compatible mappings. It can be seen in this example that $\mathrm{A}, \mathrm{B}, \mathrm{S}$ and $\mathrm{T}$ satisfy the condition (4) when $\delta(\varepsilon)=14-\varepsilon$ if $\varepsilon \geq 6$ and $\delta(\varepsilon)=6-\varepsilon$ if $\varepsilon<6$. It may also be noted that the mappings A, B, S and T do not satisfy the contractive condition (2). To see this, we can take $\mathrm{x}>17$ and $5 \leq \mathrm{y} \leq 6$, then we have $5 \leq \mathrm{d}(\mathrm{Ax}, \mathrm{By}) \leq 6$ whereas $6<\mathrm{M}(\mathrm{x}, \mathrm{y})<8$. Thus the contractive condition (4) is satisfied but not (2) when $\mathrm{x}>17$ and $5 \leq \mathrm{y} \leq 6$. Also we see that $\delta(\varepsilon)$ is neither non decreasing nor lower semi continuous. However, A, B, S and T do not satisfy the contractive condition $\mathrm{d}(\mathrm{Ax}, \mathrm{By}) \leq \phi(\mathrm{M}(\mathrm{x}, \mathrm{y}))$ since the required condition $\phi$ does not satisfy $\phi(\mathrm{t})<\mathrm{t}$ at $\mathrm{t}=6$. To verify this, we can take $8<\mathrm{x} \leq 17$ and $4 \leq \mathrm{y}<5$ then $\mathrm{M}(\mathrm{x}, \mathrm{y})=6$ and $\mathrm{d}(\mathrm{Ax}, \mathrm{By}) \rightarrow 6$ as $\mathrm{y} \rightarrow 5$. Hence we see that the present example does not satisfy the condition of any previously known common fixed point theorem for continuous mappings since neither the mappings satisfy a $\phi$-contractive condition nor $\delta$ is lower semi neither continuous nor non-decreasing.

Remarks: Pant [18] has shown that condition (iii) of the above Theorem 1 is independent of $\phi$-contractive conditions. Our result extends the results of Jha et al. [5, 6], Jha and Pant [7], Pant and Jha [17] and Pant [18] and gives a new generalization of Meir-Keeler type common fixed point theorem. Further, as various assumptions either on $\phi$ or on $\delta$ have been considered to ensure the existence of common fixed points under contractive conditions, so this Theorem 1 improves the results of Popa [21], Vats [25] and also generalizes all other similar results of fixed points. 


\section{REFERENCES}

1. Boyd, D.W. and J.S. Wong, On nonlinear contractions, Proc. Amer. Math. Soc., 20 (1969), 458 - 464.

2. Carbone, A., B.E. Rhoades and S.P. Singh, A fixed point theorem for generalized contraction map, Indian J. Pure Appl. Math., 20 (1989), 543 - 548.

3. Jachymski, J., Common fixed point theorems for some families of mappings, Indian J. Pure Appl. Math., 25 (1994), 925 - 937.

4. Jachymski, J., Equivalent conditions and Meir-Keeler type theorems, J. Math. Anal. Appl., 194 (1995), 293 - 303.

5. Jha, K., R.P. Pant and S.L. Singh, On the existence of common fixed points for compatible mappings, Punjab Univ. J. Math., 37 (2005), 39 - 48.

6. Jha, K., R.P. Pant and S.L. Singh, Common fixed points for compatible mappings in metric space, Radovi Matematicki, 12 (2003), 107 - 114.

7. Jha, K. and R.P. Pant, A generalization of a Meir-Keeler type common fixed point theorem for compatible maps, Varahmihr J. Math. Sci., 3(2003), 27 - 34.

8. Jungck, G., Compatible mappings and common fixed points, Internat. J. Math. Math. Sci., 9 (1986), 771 - 779.

9. G., Jungck, K.B. Moon, S. Park and B.E. Rhoades, On generalizations of the MeirKeeler type contractive maps: Corrections, J. Math. Anal. Appl., 180 (1993), 221 222.

10. G. Jungck and B.E. Rhoades, Fixed point for set valued functions without continuity, Indian J. Pure Appl. Math., 29(3)(1998), 227 - 238.

11. Maiti, M. and T.K. Pal, Generalization of two fixed point theorems, Bull. Cal. Math. Soc., 70 (1978), 57 - 61.

12. Meir, A. and E. Keeler, A theorem on contraction mappings, J. Math. Anal. Appl., 28 (1969), 326 - 329.

13. Pant, R.P., Common fixed points of weakly commuting mappings, Math. Student, 62 (1993), 97 - 102.

14. Pant, R.P., Common fixed points of contractive maps, J. Math. Anal. Appl., 226 (1998), 251 - 258.

15. Pant, R.P., P.C. Joshi and V. Gupta, A Meir-Keeler type fixed point theorem, Indian J. Pure Appl. Math., 32(6) (2001), 779 - 787.

16. Pant, R.P., A.B. Lohani and K. Jha, Meir-Keeler type fixed point theorem and reciprocal continuity, Bull. Cal. Math. Soc., 94(6) (2002), 459 - 466.

17. Pant, R.P. and K. Jha, A generalization of Meir-Keeler type common fixed point theorem for four mappings, J. Nat. Phys. Sci., 16(1-2) (2002), 77 - 84.

18. Pant, R.P., Meir - Keeler type fixed point theorems and dynamics of functions, Demonstratio Math., 36(1)(2003), 199 - 206.

19. Park, S. and J.S. Bae, Extension of a fixed point theorem of Meir-Keeler, Ark. Math., 19 (1991), 223 - 228.

20. Park, S. and B.E. Rhoades, Extension of some fixed point theorems of Hegedus and Kasahara, Math. Seminar Notes, 9 (1981), 113 - 118. 
21. Popa, V., A generalization of Meir - Keeler type common fixed point theorem for four non-continuous mappings, Sarajevo J. Math., 1(13)(2005), 135 - 142.

22. Rhoades, B.E., Contractive definitions and continuity, Contemporary Math., 72 (1988), 233 - 247.

23. Singh, S.L. and S. Kasahara, On some recent results on common fixed points, Indian J. Pure Appl. Math., 13 (1982), 757 - 761.

24. Singh, S.L., and S.N. Mishra, Remarks on Jachymski's fixed point theorems for compatible maps, Indian J. Pure Appl. Math., 28(1997), 611 - 615.

25. Vats, R.K., Weakly compatible maps in metric spaces, J. Indian Math. Soc., 69(14)(2002), $139-143$. 